\title{
The Un-Common Leopard: presence, distribution and abundance in Gallies and Murree Forest Division, Northern Pakistan
}

\author{
Muhammad Asad', Muhammad Waseem², James G. Ross', Adrian M. Paterson' \\ I Department of Pest-management and Conservation, Faculty of Agriculture and Life Science, Lincoln Uni- \\ versity, Ellesmere Junction Road/Springs Road, PO Box 85084, Canterbury, New Zealand 2 WWF Pakistan, \\ Pakistan Academy of Science building, $3^{\text {rd }}$ Constitution Avenue, G-5/II, Islamabad, Pakistan
}

Corresponding author: Muhammad Asad (masadj@yahoo.co.uk)

Academic editor: C. Knogge | Received 30 December 2018 | Accepted 21 October 2019 | Published 20 November 2019

http://zoobank.org/582405CE-5C6B-45E9-873D-DD619E7F234E

Citation: Asad M, Waseem M, Ross JG, Paterson AM (2019) The Un-Common Leopard: presence, distribution and abundance in Gallies and Murree Forest Division, Northern Pakistan. Nature Conservation 37: 53-80. https://doi. org/10.3897/natureconservation.37.32748

\begin{abstract}
The leopard Panthera pardus is thought to be sparsely distributed across Pakistan and there is limited understanding of the demographic structure and distribution of the species in this country. We conducted a study, from April to July 2017, and, from March to June 2018, in the northern Pakistan region to establish the presence and distribution of leopards, mindful at the outset of their abundance in that region. The presence of leopards was confirmed in the Swat, Dir and Margalla Hills region. The leopard population in Gallies and Murree Forest Division was preliminarily assessed via camera-trapping. As a result, a total of 63 potential areas of leopard population were identified initially. The leopard was photo captured at 27 locations (hotspots) with 34 capture events yielding 195 images over the course of 3,022 active trap-nights. Camera trap images were examined to identify leopard individuals using their rosette patterns on both the left and right flanks and the dorsal side of the tail. Ultimately, 15 leopard individuals were identified during the first survey period of the study and four individuals were recaptured in the second survey period, together with three new individuals. The detection probability of individual leopards from MARK varied from 0.10 and 0.20 with a population size (preliminarily estimated to be $16-25(\mathrm{SE}=3.18)$ in 2107 and $7-13(\mathrm{SE}=1.87)$ in 2018. This gave a density of 4.5 to 9.5 leopards $/ 100 \mathrm{~km}^{2}$, respectively. A home range of various individual leopards was found to extend from the Gallies Reserved Forest to the extended corridors of Guzara Forest. In general, this study suggests that the Guzara Forest is crucially important for the conservation of leopards in the region as this area allows them extended movement while searching for food and mates.
\end{abstract}

Copyright Muhammad Asad et al. This is an open access article distributed under the terms of the Creative Commons Attribution License (CC BY 4.0), which permits unrestricted use, distribution, and reproduction in any medium, provided the original author and source are credited. 


\section{Keywords}

Leopard, Panthera pardus, individual recognition, camera trapping, presence/absence, Northern Pakistan

\section{Introduction}

The leopard is one of the most widespread territorial mammalian carnivores on earth (Nowell and Jackson 1996; Hunter et al. 2013; Ripple et al. 2014). The solitary and opportunistic nature of this species enables it to be highly adaptable to different environmental conditions, which range from Africa to the Middle East, Asia, through to the far north of Russia, and then eastwards to Southeast Asia (Nowell and Jackson 1996; Dickman and Marker 2005; Stein and Hayssen 2013). Leopards are found in a wide range of habitat types from tropical, subtropical and humid forests, mountain, savannah and scrub through to deserts (Nowell and Jackson 1996; Sanei et al. 2011a; Stein and Hayssen 2013; Shehzad et al. 2014; Athreya et al. 2016). They feed on a broad range of prey species, such as ungulates, birds, rodents and reptiles (Sanei et al. 2011b; Mondal et al. 2012a; Shehzad et al. 2014; Kshettry et al. 2018). Leopards are wide-ranging carnivores. They defend their territories and maintain their home ranges for natural ranging and foraging activities. Brown and Orians (1970) define territories as 'a fixed, exclusive area with the presence of a defence that keeps out rivals'. The concept of a home range is described as an area in which the animal pursues food or engages in routine activity (Jewell 1966; Burt 1943). Leopards also persist in high 'human-use' areas (Athreya et al. 2016; Kshettry et al. 2017). However, despite all these flexible characteristics, the leopard population is declining throughout their species range. As a result, leopards are now absent from $63-75 \%$ of their historical range, with the highest rate of decline in Asia where several subspecies are characterised as endangered (Stein and Hayssen 2013). Jacobson et al. (2016) demonstrated that leopards have disappeared from $83-87 \%$ of their former range in Asia, while the distribution in Africa has declined to around $48-67 \%$ of their former distribution (Sheikh and Molur 2004; Ghalib et al. 2007; Laguardia et al. 2015; Sanei et al. 2016).

The main threats to leopards include habitat loss and degradation, developments close to protected areas, rapid depletion of the natural prey base, poaching, and conflicts with livestock causing revenge killing by the livestock owners (Fahrig 2003; Athreya and Belsare 2007; Mondol et al. 2009; Sanei and Zakaria 2011c; Sanei et al. 2012; Kabir et al. 2013; Qi et al. 2015). Isolation and fragmentation of habitats are further threatening the leopards within their remaining ranges by undermining the genetic health of the populations (Spong et al. 2000; O'Brien and Johnson 2005; Quaglietta et al. 2013).

In this study, we aim to establish baseline information for long-term monitoring of leopards to further improve the management and conservation of the species in the Gallies and Murree Forest Division in northern Pakistan. The findings will also provide a general understanding about leopard habitats in Pakistan. The objective of this current study is to establish baseline information for the long-term monitoring and effective management of leopard conservation in the Gallies and Murree Forest 
Division. The approach will provide a model for other leopard habitats in Pakistan. This approach also provides additional information on the presence of prey species for leopards in the area.

\section{Leopards in Pakistan}

In Pakistan, leopards were once widely distributed across the country in a variety of habitats and regions such as Punjab Baluchistan, Khyber Pakhtunkhwa, Sindh, Azad Jammu and Kashmir (Roberts 1977). Leopards are now known to be sparsely distributed across the country (Sheikh and Molur 2004; Henschel et al. 2008; WWF-Pakistan 2014). A principal reason for this is deforestation (only about $2.5 \%$ of the original forests remain) with an annual rate of decline of forest cover of $2.1 \%$ (FAO 2007). The erosion of land as well as landslides, mainly due to high deforestation, private land ownership in the surrounding Guzara Forest of protected areas, and the right of local communities to collect fuel wood within these zones, are further threatening these habitats (Ashraf et al. 2014).

In Pakistan, the leopard is classified as critically endangered in the Conservation Assessment and Management Plan developed by the IUCN (Sheikh and Molur 2004; Henschel et al. 2008). As habitats in Pakistan are increasingly populated by humans, there has been a decline in the local leopard populations and ranges, as well as their prey species, and livestock-leopard conflicts have increased (Uphyrkina and O'Brien 2003; O’Brien and Johnson 2005; Mondol et al. 2009; Ripple et al. 2014). Leopard attacks on humans occur occasionally across northern Pakistan (Lodhi 2007) and several leopards are poisoned or shot annually in reprisals (Muhammad Asad, pers. obs as Conservation Officer (2013-2014). Six leopard mortalities were reported in Ayubia National Park and the surrounding Guzara Forest between November 2011 and December 2012 after two children were attacked and killed (Khyber-Pakhtunkhwa Wildlife Department and WWF-Pakistan). It is likely that many leopard mortalities are not reported (Personal communication). For example, we found two leopard bodies with their skin removed in the Gallies Forest Division during our data collection for this study that had not been reported to Khyber-Pakhtunkhwa Wildlife Department.

Other threats to leopards include poaching, trapping cubs for animal dealers, and the trade of body parts and skins. Skin, claws, and teeth are available for sale in markets in northern Pakistan (Personal communication. Theile 2003; Ripple et al. 2014). Leopards are protected under the law but rules and regulations are poorly implemented on the ground, as there are no checks and balances within the limited management capacity of local wildlife departments.

The lack of a compensation programme to recompense livestock owners for relative losses, e.g. in Swat and Dir regions, or slow compensation procedures, e.g. in Gallies Forest, further undermine leopard conservation by causing local people to resent leopards (Shehzad et al. 2014).

Leopard vulnerability to extinction is higher than for other cats due to their wideranging natural movements for food and mates as this exposes them to higher risks 
(Cardillo et al. 2004). Stein et al. (2016) suggested a sparse distribution of leopards in Waziristan, Sindh, Punjab, and Ayubia National Park. However, knowledge of species abundance and density is vital for conservation efforts at both the species and population levels (Williams et al. 2002; Royle and Dorazio 2008). Knowledge about the status of leopard distribution and density is vital for successful conservation and management programmes (Borah et al. 2013; Jacobson et al. 2016). This allows for the allocation of appropriate resources, the development of effective mitigation measures, adaptive responses by wildlife managers in case of conflict, and the prioritisation of conservation efforts in high-value habitats.

In Pakistan, there are no robust estimates for the current distribution and density of leopards. Phylogenetic analysis confirms the presence of two subspecies $P$. $p$. saxicolor, P. p. fusca (Asad et al. 2019). Few studies on diet analysis and conservation have been conducted that address human-leopard conflicts (Lodhi 2007; Kabir et al. 2013; Shehzad et al. 2014), although these studies at least indicate the presence of leopards in different areas (e.g. Galyat, Azad Kashmir and Sindh). Khan et al. (2013) assessed the current distribution and status of mammals, including leopards, in the Khirthar protected area. Anecdotally, the leopard is assumed to have a stable population in northern Pakistan, including the Swat, Dir, and Margala Hills regions (Shehzad et al. 2014). However, the local people and the Wildlife Department in Khyber Pakhtunkhwa (Province) believe that the species has disappeared from the Swat and Dir districts. Recently, the presence of leopards has been confirmed in the Ayubia National Park and the surrounding Forest Reserve of Khyber Pakhtunkhwa and Murree following the detection of leopard scats (Shehzad et al. 2014). Observations of human-leopard conflicts have been made in the Machiara National Park, Azad Jammu and Kashmir, and the Ayubia National Park by Lodhi (2007) and Kabir et al. (2013).

Estimating the presence of leopard populations is difficult as they have large ranges in their natural habitats and usually occur at low densities (Tobler and Powell 2013). Observations of human-leopard conflicts have been made in Machiara National Park, Azad Jammu and Kashmir, and Ayubia National Park, by Lodhi (2007), Kabir et al. (2013) and Shehzad et al. (2014), who analysed the diet of leopards in Ayubia National Park. Many of these also act as conservation studies and so are important for understanding the ecology and behaviour of the top predators in specific ecosystems and for the effective conservation of the species (Brodie 2009). Meetings and semistructured interviews have been used to ascertain leopard presence-absence from regions (Abdollahi 2015). Semi-structured questionnaires were used to collect presenceabsence information from villagers in Swat (Ahmad et al. 2014) and their presence was confirmed by installing camera-traps to collect spatial and temporal information and develop a picture of species distribution (Mondal et al. 2012b). The presence-absence data of a species is vital for researchers in conservation-related efforts, particularly for cryptic carnivores (MacKenzie 2005). Therefore, sampling with multiple procedures and combining sampling processes is often required to construct reliable presenceabsence datasets (Manly et al. 2002; MacKenzie 2005).

Obtaining information about abundance, predictability, and site occupancy is challenging over the range of habitats that leopards inhabit, as they have a wide range 
and occur in low densities (Balme et al. 2009; Kery et al. 2010). Closed populations and capture-recapture frameworks have been used to estimate the abundance of many elusive carnivores, such as tigers (Panthera tigris) and leopards (Karanth 1995; Wang and Macdonald 2009; Wegge et al. 2009), jaguars (Sollmann et al. 2013; Tobler and Powell 2013), ocelots (Trolle and Kery 2003), clouded leopards (Borah et al. 2013), and snow leopards (Alexander et al. 2016). These frameworks require all individuals to be identifiable and to have reasonably high capture probabilities, with a random sampling of individuals (Harmsen et al. 2011).

Estimates of felid presence include abundance and density estimates for the common leopard and the clouded leopard in Manas National Park (Borah et al. 2013), estimates of a tiger population from camera-trap data (Karanth 1995; Wang and Macdonald 2009), estimates of jaguar density with camera-traps (Tobler and Powell 2013), and estimates of grazing mammal densities using camera-traps (Rowcliffe et al. 2008).

Camera-trapping has recently emerged as a promising method for estimating the abundance of elusive carnivore species in ecological sciences by identifying individuals through their unique pelage patterns with minimal disturbance (Karanth 1995; Heilbrun et al. 2003; Henschel and Ray 2003; Alonso et al. 2015). Camera-traps are a useful technique for observing and assessing animal information in situ (Khorozyan et al. 2008; Balme et al. 2009; Tobler and Powell 2013; Bashir et al. 2014). As such, camera-traps have been adopted widely for detecting the presence, abundance, and the proportion of sites occupied by a species (Kery et al. 2010). Camera-traps and fieldbased surveys obtain sufficient spatial and temporal information for the species that are present within the sample unit to estimate the total population for an entire area (Henschel and Ray 2003; Silver et al. 2004; Jackson et al. 2006; Rowcliffe et al. 2008; Maffei and Noss 2008; Wang and Macdonald 2009; Sundaresan et al. 2011; Sollmann et al. 2013; Karki et al. 2013; Bino et al. 2014). As a territorial animal, a leopard generally does not leave a territory unless removed by humans or killed. Males usually show less variation in movement patterns than females, although the distance travelled by both sexes is similar, except around birth (Morten and Per 2005). We assumed that any differences in movement patterns between the sexes would not affect our closed population assumption because we sampled over the same season. Encounter histories were constructed from individual leopards observed in each sampling period (Silver et al. 2004; Wang and Macdonald 2009; Alonso et al. 2015).

Capture-recapture methods have been widely used to estimate abundance and density from camera photos in many carnivores, such as the snow leopard (Panthera uncia), tiger (Panthera tigris) (Sharma et al. 2010), bobcat (Lynx rufus), (Alonso et al. 2015), black bear (Ursus americanus) (Fusaro et al. 2017), jaguar (Panthera onca), (Silver et al. 2004) and common leopard (Panthera pardus) (Harihar et al. 2009). MARK capturerecapture (CMR) has also helped quantify distribution and abundance of prey (Otis et al. 1978; Karanth 1995; Soisalo and Cavalcanti 2006; Jackson et al. 2006; Balme et al. 2009; Alonso et al. 2015). The CMR framework presents an advantage if individual animals are able to be identified from their unique pelage patterns as this allows individual encounter histories to be constructed on different occasions using this framework (Soisalo and Cavalcanti 2006; Alonso et al. 2015). Population size and capture prob- 
abilities of the target species may be estimated (Alonso et al. 2015) and produce robust population estimates for many elusive carnivores (Heilbrun et al. 2003; Jackson et al. 2006; Balme et al. 2009; Rozhnov et al. 2015; Thornton and Pekins 2015).

The same robust approach was used in this study to estimate the abundance of common leopards in the Gallies and Murree Forest Division of Pakistan. A CMR model combined with Arc GIS mapping was used. CMR analysis is used to estimate abundance for closed and open populations (Karanth 1995; Borah et al. 2013; Alonso et al. 2015). A closed population allows a more robust estimate of population size than an open model, assuming there are no births, deaths or migration during the study period (Otis et al. 1978; White and Burnham 1999; Jackson et al. 2006; Balme et al. 2009). Several studies have used the average of mean maximum distance moved MMDM or $1 / 2$ MMDM for individuals captured by more than one camera-trap. A buffer is then estimated around each camera-trap to calculate the estimated sample area (ESA) (Karanth and Nichols 1998; Sollmann et al. 2013; Tobler and Powell 2013). The ESA is considered more accurate if calculated with the buffer of a full MMDM, which is believed to be larger for species with large home ranges (Silver et al. 2004; Soisalo and Cavalcanti 2006; Sollmann et al. 2013). A small sample area could mislead and allow overestimation of a population size (Harmsen et al. 2011; Tobler and Powell 2013; Thornton and Pekins 2015). We estimated the number of leopards that we didn't see and added to those that we did (abundance) from CMR and then calculated how many there are in an area (density).

\section{Materials and methods}

\section{Study area}

The study was conducted in northern Pakistan, across the Gallies Forest Division $\left(34^{\circ} 04^{\prime} 07^{\prime \prime} \mathrm{N}, 73^{\circ} 41^{\prime} 03^{\prime \prime E}\right)$, Murree Forest Division (3352'26.34"N, 73²3'42.21"E), Swat $\left(35^{\circ} 01^{\prime} 10.70^{\prime \prime N}, 72^{\circ} 08^{\prime} 50.93^{\prime \prime E}\right)$, and Dir districts (35 $51^{\prime} 11.19^{\prime \prime N}$,

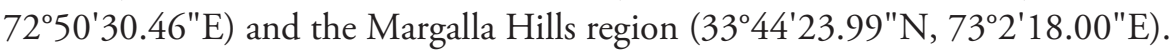

The area of the Gallies Forest Division comprises a 15,716 ha Reserve Forest and a 8,224 ha Guzara Forest, which is also managed by the Khyber Pakhtunkhwa Forest Department. The Ayubia National Park is located in the Forest Reserve of Gallies Forest Division with a total area of 3,312 ha surrounded by other Reserved Forest. The Guzara Forest of the Gallies Forest Division is linked to the Reserved Forest that is surrounded by five villages. The boundaries of the Reserve Forest and Guzara Forest are disputed (Lodhi 2007). Guzara Forest acts as a corridor that allows species to extend their movement into an area with low human densities while searching for food (Fig. 1). The main source of income for local people is seasonal tourism and livestock (Lodhi 2007). The total area of the Murree Forest Division is 19,000 ha and comprises Reserve Forest, Protected Forest, and Guzara Forest. The Murree Forest Division manages 22 Protected and 23 Reserve Forest patches (Ashraf et al. 2014; Ahmed and Mahmood 1998). Most of the available knowledge on Pakistani leopard presence-absence, diet and human leopard conflicts are only available for these places, so it is assumed that they have rela- 
tively stable leopard populations (Shehzad et al. 2014). The total area of the Margalla Hills is 17,386 ha. The Margalla Hills is an extension of the Islamabad Wildlife sanctuary that includes Shakar Parian Hills and Rawal Lake (WWF-Pakistan).

Our study area lies in the outer Himalayas in the sub-tropical continental highlands and encompasses two distinct ecological zones, 'moist temperate coniferous forests' and 'chir pine subtropical forests' (Ashraf et al. 2014). Mammals within the sampled area include the leopard cat, Prionailurus bengalensis, jackal, Canis aureus indicus, rhesus monkey, Macaca mulatta, marten, Martes flavigula, Indian palm civet, Paradoxurus hermaphroditus, Himalaya palm civet Paguma larvata and red fox, Vulpes vulpes (Shehzad et al. 2014). There are no recent forest maps in Pakistan that include Guzara Forest, except for the Murree Forest Division, and the Ayubia National Park that were developed by WWF-Pakistan during delineation of the forest boundaries (Ashraf et al. 2014; Abbas et al. 2010). We delineated the boundary between Reserved Forest and Guzara Forest with the help of ArcGIS from the old maps provided by the Khyber-Pakhtunkhwa Wildlife Department (Fig. 1).

\section{Questionnaire survey}

Between April 2017 and March 2018, we conducted questionnaire surveys $(n=1028)$ among local communities living close to the study areas of Galyat, Murree, Margalla Hills, Swat and Dir where they were asked to identify potential sites for detecting leopard presence. Around 30 questionnaires were completed at each village; in total, there were 35 villages. These villages were randomly selected from the union council map and, within each village, interviewees were randomly selected. The following information was collected: livestock depredation, time of attack, and type of injury, e.g. bite marks on neck or missing dogs or human casualties. Where possible, we validated the collected data by visiting each site as well as interviewing local Khyber Pakhtunkhwa Wildlife Department staff and nomads.

A total of 69 leopard records were identified from the questionnaire surveys. Out of these, 39 records were from Galyat and Murree, 24 from Swat and Dir, and 6 from Margalla Hills National Park. Six locations were later discarded from Galyat region due to the doubling of locations with different names, giving a final count of 63 sampling sites. Data were used to choose sites for future tracking surveys and cameratrapping (Fig. 1).

\section{Tracking survey}

We conducted surveys in selected sites where leopards had been reported. Each trail surveyed was 4-10 km in length and was completed between 0700 and $1700 \mathrm{hr}$. We searched trails for signs of scats, territorial markings, and tree scratches that implied leopard presence-absence. Signs of leopards were recorded and photographed. Areas were identified on the trails that had frequent leopard movements (Fig. 2). Such loca- 

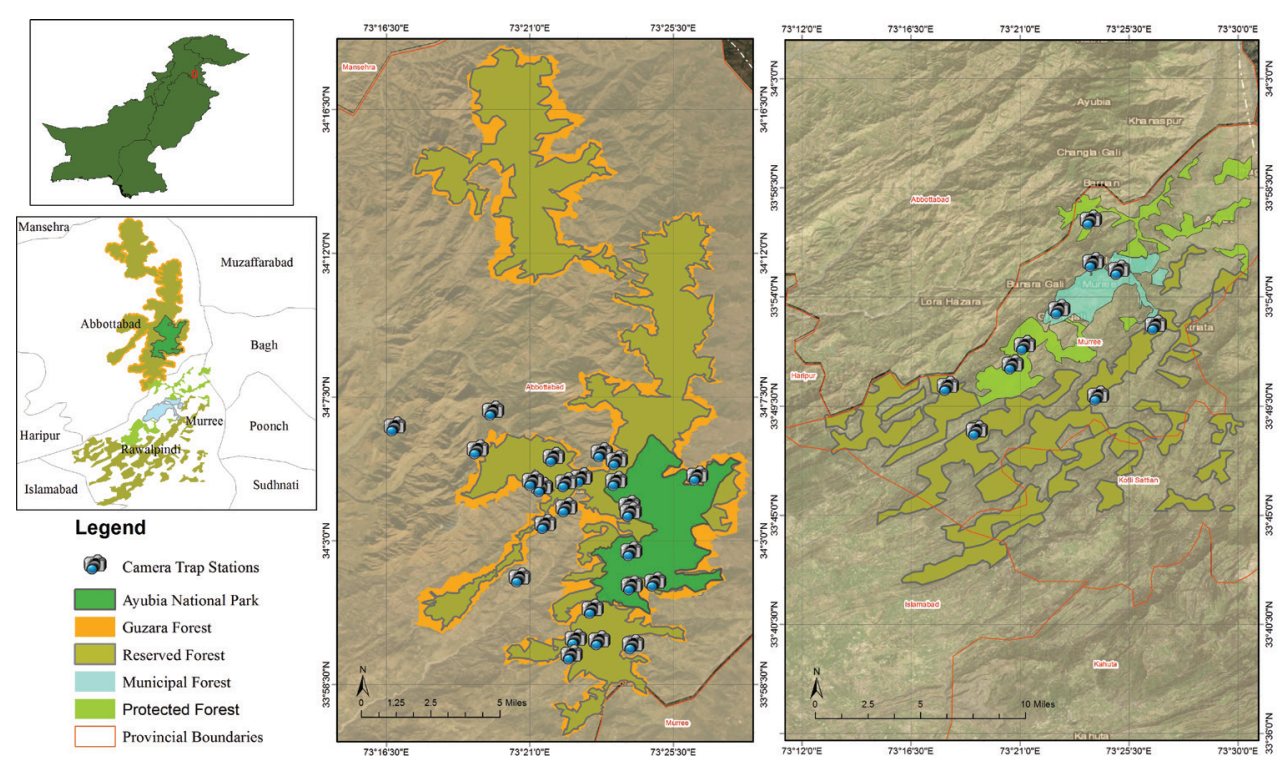

Figure I. Sampling locations of the camera-traps survey in Gallies Forest (Ayubuia National Park, surrounding Reserved Forest and Guzara Forest), and Murree Forest (Protected, Reserved and Municipal Forest) A Country map (top left - green) followed by B study area showing different city boundaries C showing legend

tions were used as sites for the camera-traps. We were not able to sample from the Margalla Hills Region due to the insufficient number of camera-traps available and relied on transect sampling data for confirmation of leopard presence-absence.

Secondary data on leopard attacks on humans that resulted in injuries or deaths, cases of revenge killing, as well as leopard natural deaths when detected, were collected from Khyber Pakhtunkhwa Wildlife Department and WWF -Pakistan for the years 2005-2018 for the district of Abbottabad.

\section{Camera trapping}

We conducted camera-trap surveys along the tracking trails in 63 locations across Galyat and Muree, Swat and Dir. Camera-trapping was conducted, from April to July 2017 and from March to June 2018. The survey was carried out in summer because of heavy snowfalls in winter. The study area was divided into three sections: Galyat and Murree, Swat and Dir, and the Margalla Hills. We deployed 14 camera-traps in two sections (a total of 63 locations) for a period of 14 days at $20-40 \mathrm{~cm}$ above the ground (Balme et al. 2009).

Leopards are generally nocturnal and most active during dawn and dusk (RayBrambach et al. 2018). Thus to extend the battery life, the camera-traps were only active between $6 \mathrm{pm}-8 \mathrm{am}$. Nomadic farmers and their grazing livestock were generally active during the daytime. Also, male and female leopards have different activity patterns over a 24-hour period. (Ray-Brambach et al. 2018). The camera-traps were 


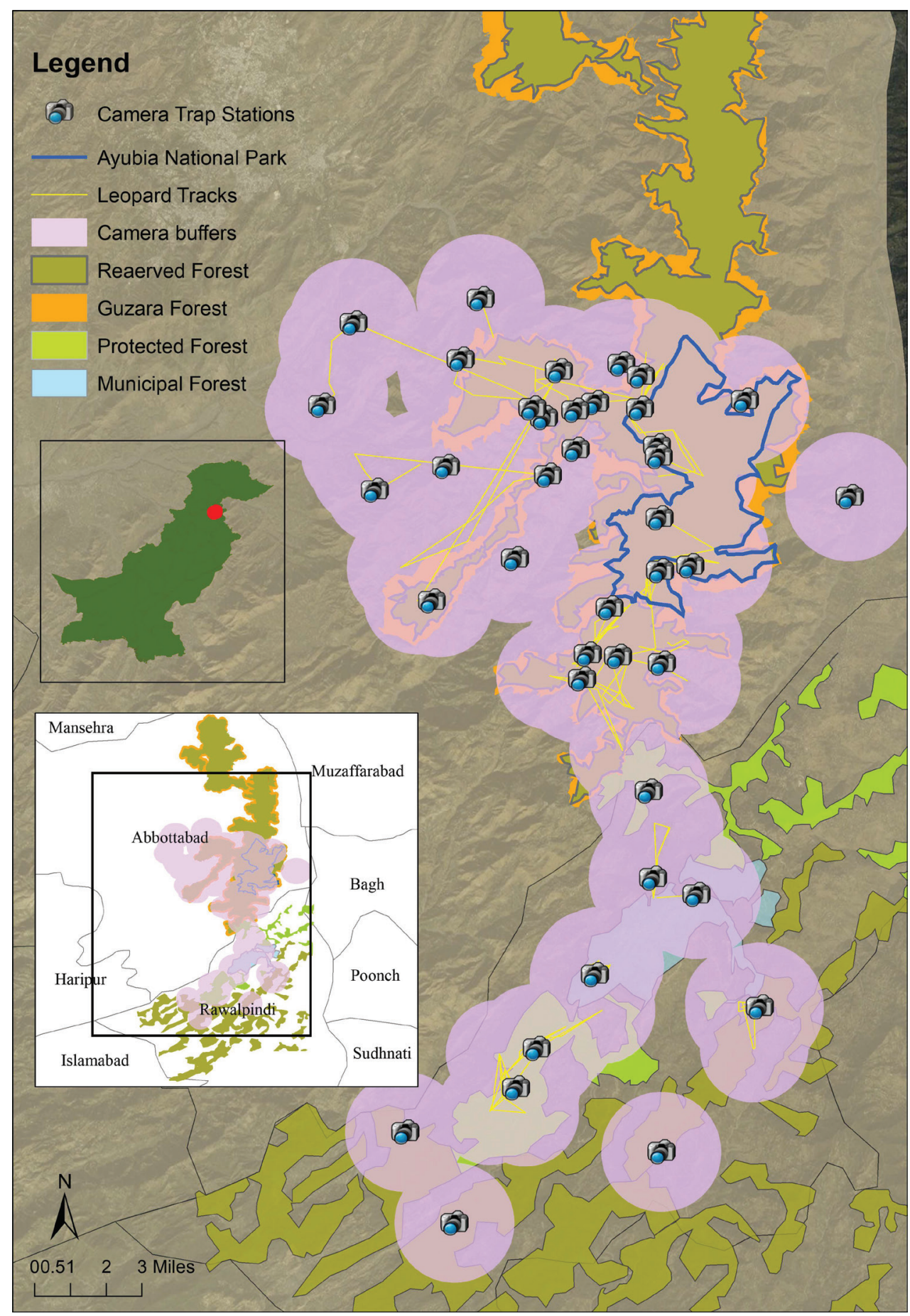

Figure 2. Representation of the study area with the effective sample area of the different hotspots identified. The buffer shows the MMDM from the leopards captured more than once from different locations. The hotspots were linked with the number of signs found on each track. The trails were named by the closest village, and the leopards were named according to the track on which they were photographed. 
checked every two weeks to replace the batteries and re-position the cameras, if required. Camera angles, trigger speed, detection zones and time-lapse between the triggers were set according to the previous literature about installation considerations (see Rovero et al. 2013; Trolliet et al. 2014 and details below).

Two cameras, one on either side of the trail, were placed at each site facing each other, to capture both flanks of a passing leopard.

This allowed the identification of individual leopards from their unique rosette of spots (Karanth 1995; Heilbrun et al. 2003; Silver et al. 2004). Cameras were set with a high trigger speed (0.2-0.8 seconds) with a recovery time of 1 and 0.5 seconds, respectively, for the two cameras. Three photos per trigger were taken to capture leopards as they move faster on trails than in other topography types (Scheibe et al. 2008). The photographs were then manually examined for leopard detections. We relied on transect sampling data in the Margalla Hills as we did not have a sufficient number of camera-traps or time to complete the standard method.

\section{A preliminary abundance estimate}

To estimate the abundance in Galyat and Murree, where the leopard population is considered stable (Shehzad et al. 2014), camera-trapping was repeated for a second season, from March-June 2018. Camera-traps were also placed in the five connecting trails identified earlier through the preliminary survey in the locations where no leopard signs were found. This was to satisfy the assumption that no animals have zero capture probability (Balme et al. 2009) as leopards may use areas but leave no sign. Neither are they detected by locals.

The spacing of camera-traps was based on the minimum home range recorded for an adult female leopard with cubs, 5.2-6.6 km² in Nepal (Morten and Per 2005) and $8 \mathrm{~km}^{2}$ in north-central Namibia (Dickman and Marker 2005). Most studies show that the home range size varies in female leopards around birthing time (Rozhnov et al. 2015) while the distribution of prey and the location of females most affects the home range size in males (Bailey 1993; Odden and Wegge 2005). Since the width of trails varies from $0.5-3$ metres, it was not practical to obtain detailed images of both flanks on trails with less than $1 \mathrm{~m}$ width. On wider trails (i.e. over $1 \mathrm{~m}$ width), the cameras were set at a $90^{\circ}$ angle from the direction of the trail to obtain images of both flanks of every passing leopard. It was difficult to obtain detailed images of both flanks on trails less than $1 \mathrm{~m}$ in width. Cameras were set at a $45^{\circ}$ angle on trails with less than $1 \mathrm{~m}$ width for obtaining clear images required for the subsequent individual identifications.

The sex of individuals was identified by their distinctive morphological features (Balme et al. 2012), and each identified individual was given a name based on the track that they were recorded in. Camera-traps were moved frequently from one location to another after 14 days, as we discovered new trails with leopard sign. Individual leopards were identified from their unique rosette patterns, based on the guidelines from Heilbrun et al. (2003) and Jackson et al. (2006). The independence of events was addressed on the basis of instructions provided in the same references. We used the 
image manipulation programme GIMP, available online at http://gimp.org to digitise unique noticeable spots found in different areas of the body. We analysed spot to spot to differentiate individuals from one another.

\section{Preliminary mark-recapture practice}

The MARK Program (Version 8.2; White and Burnham 1999) was used to estimate the abundance of leopards (White and Burnham 1999; Alonso et al. 2015). As a requirement of the model, the population is assumed to be closed with no natural mortality and permanent movements into or out of the survey area over this period. We believe that we met this assumption because of the short duration of the study.

The capture histories were constructed for 14-day sampling periods for each leopard simply by defining each day and night as a single session, resulting in 14 sampling occasions, to provide the maximum number of capture histories. We fitted seven priori models (plausible simple models with different combinations of covariates) to the data, which represent different combinations of factors that may affect capture probabilities: behaviour (probability of recapture of a different individual comparing to the probability of the first capture), individual heterogeneity, year, and survey night. The models are notated with the factors affecting capture probability indicated in parentheses. The data from each year were entered as different groups in the software to enable parameters to be shared between the two years. Models were compared using AIC, and model averaging was used to obtain overall abundance estimates. To estimate density from the abundance data, we determined the effective study area by calculating the buffer (the average of the maximum distance travelled between capture locations Fig. 3) around each camera-trap, as determined by MMDM. (Sollmann et al. 2013; Tobler and Powell 2013; Karanth and Nichols 1998). The density of leopards was calculated from the abundance data generated by Program MARK D = N/A, where $A$ is the area covered during the sampling period (effective study area) and $\mathrm{N}$ is the number of leopards estimated by Program MARK.

\section{Results}

\section{Presence and absence}

In Galyat and Murree we recorded 192 leopard photos over 1,930 trap-nights, representing a capture success of 9.94 captures/100 trap-nights. We also located 58 territorial markings that included scats, scrapes and tree scratches. Most camera-trap photos $(67 \%)$ were caused by the movement of local people and mostly from four camera stations Lalazar track, Pipeline track, Baragali track and Nagribala track. Non-target species, such as the fox, jackal, porcupine, wild boar, martens, rhesus monkey, and civet, comprised 21\% of the images. Domestic livestock (goats and cows) represented $8.7 \%$ of the total images; false triggers, where there was no obvious reason for activation, comprised a relatively low $2 \%$ (Table 1 ). 


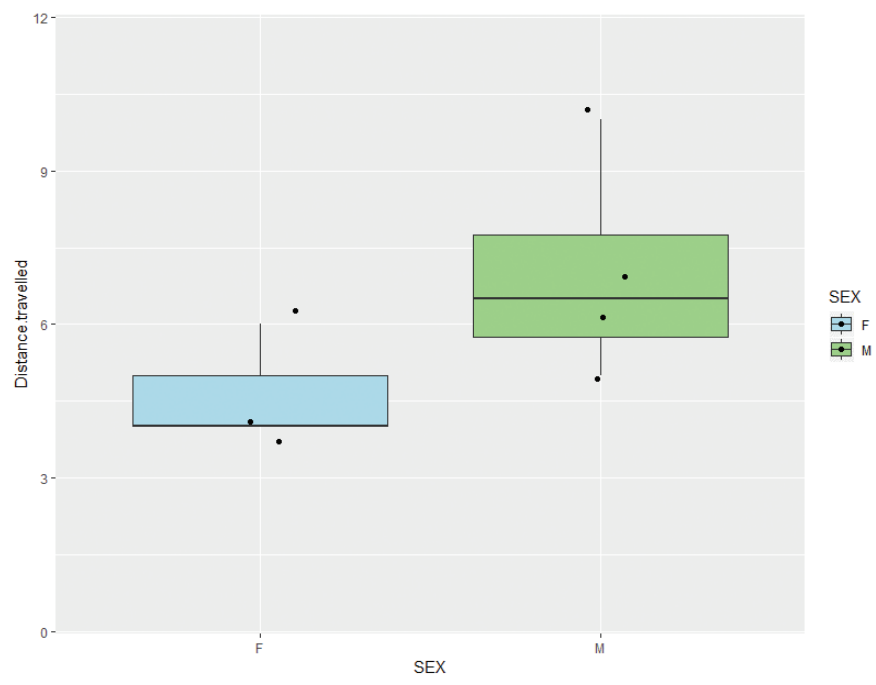

Figure 3. Box plot showing distance travelled by identifiable male and female leopards captured at multiple locations in our study area.

In Swat and Dir we recorded one leopard at one camera-trap station from Shangla (Swat) over the 1,092 traps nights and located only two territorial markings in Nehagdara (Upper Dir) while scoping trails for leopard signs. We collected a total of 11,806 photographs, which mainly comprised the movements of livestock (sheep, goats, and horses) of the nomads (34\%), local community, including hunters, contributed $32 \%$ of the total images. Nomads are people who travel from the plains to the hills during the summer to graze their herds (sheep, goat, cattle) and local communities are the people resident in the area for all of the year. False triggers and non-target species (e.g. foxes, jackals, porcupines, dogs, and domestic cats represented $18 \%$ and $14 \%$ of the total images respectively (Table 2)).

In the Margalla Hills, we conducted a walking survey for leopard signs at six locations across the area along 4-10 km-long transects, between 0700 and $1700 \mathrm{hr}$. We found four signs of leopard territorial marking as well as scats on four survey sites, which confirmed the presence of leopards in the area.

\section{Individual recognition}

We examined each individual leopard image for their unique spot pattern. The most distinctive body parts used for identification and comparison were the left and right flanks and the dorsal surface of the tail (Figs 4-6). A total of 15 individuals were identified during the first survey and four of them were recaptured in the second survey along with three new individuals. Leopards were recorded from 27 out of 39 hotspots (potential area of high leopard use) identified in the questionnaires or by previous 
Table I. Summary of the camera-trap images from 39 hotspots/trails for common leopard and nontarget species showing active trap-nights, total photos and false images in Gallies and Murree Forest Division 2017 and 2018.

\begin{tabular}{|c|c|c|c|c|c|c|c|c|c|c|c|}
\hline \multirow{2}{*}{$\begin{array}{l}\text { Sampling } \\
\text { period }\end{array}$} & \multirow{2}{*}{$\begin{array}{c}\text { Hotspots/ } \\
\text { trails }\end{array}$} & \multirow{2}{*}{$\begin{array}{c}\text { Active } \\
\text { trap- } \\
\text { nights }\end{array}$} & \multirow{2}{*}{$\begin{array}{c}\text { Total } \\
\text { photos }\end{array}$} & \multirow{2}{*}{$\begin{array}{c}\text { False } \\
\text { images }\end{array}$} & \multicolumn{3}{|c|}{ Non target capture } & \multicolumn{4}{|c|}{ Common leopard } \\
\hline & & & & & $\begin{array}{l}\text { Other } \\
\text { species }\end{array}$ & Livestock & $\begin{array}{c}\text { Local } \\
\text { community }\end{array}$ & Photos & $\begin{array}{c}\text { Captures } \\
\text { events }\end{array}$ & Initial capture & Un- identified \\
\hline 2017 & 39 & 950 & 21,410 & 281 & 3,480 & 1,186 & 16,342 & 121 & 33 & 15 & 7 \\
\hline \multirow[t]{2}{*}{2018} & 39 & 980 & 8,221 & 328 & 2,927 & 1,455 & 4,040 & 71 & 21 & $\begin{array}{l}\text { Recaptured- } \\
\text { initial capture }\end{array}$ & 4 \\
\hline & & & & & & & & & & 3 & \\
\hline
\end{tabular}

Table 2. Summary of the camera-trap images and trail scoping for presence-absence of the common leopard and non-target species at different location sampling periods and sites, showing active trap-nights, total photos and false images in 2017 and 2018.

\begin{tabular}{|c|c|c|c|c|c|c|c|c|c|c|}
\hline \multirow[t]{2}{*}{ Location } & \multirow[t]{2}{*}{ Sampling period } & \multirow{2}{*}{$\begin{array}{c}\text { No of } \\
\text { sites }\end{array}$} & \multirow{2}{*}{$\begin{array}{c}\text { Active } \\
\text { trap-nights }\end{array}$} & \multirow{2}{*}{$\begin{array}{c}\text { Total } \\
\text { photos }\end{array}$} & \multirow{2}{*}{$\begin{array}{c}\text { False } \\
\text { images }\end{array}$} & \multicolumn{3}{|c|}{ Non target capture } & \multicolumn{2}{|c|}{ Common leopard } \\
\hline & & & & & & $\begin{array}{l}\text { Other } \\
\text { species }\end{array}$ & Livestock & $\begin{array}{c}\text { Local } \\
\text { community }\end{array}$ & $\begin{array}{c}\text { Photos } \\
\text { event }\end{array}$ & $\begin{array}{c}\text { Territorial } \\
\text { markings }\end{array}$ \\
\hline $\begin{array}{l}\text { Galyat and } \\
\text { Murree }\end{array}$ & $\begin{array}{l}\text { April - July } 2017 \\
\text { March - July } 2018\end{array}$ & 39 & 1,930 & 30,231 & 609 & 6,407 & 2641 & 20,382 & 192 & 58 \\
\hline Swat and Dir & March - June 2018 & 24 & 1,092 & 11,806 & 2,140 & 1,677 & 4,116 & 3,870 & 3 & 2 \\
\hline Margalla Hills & March - June 2018 & 6 & - & - & - & - & - & - & & 4 \\
\hline
\end{tabular}

signs). A total of 18 individuals were identified based on their unique rosette patterns. Leopard ID 01, an adult male, was observed on three separate trails that were adjacent. Four males and three females were observed on two trails with overlapping home range, and the rest of the identified leopards were observed on individual trails. Leopards from eight hotspots were not identified during the second year, as there were no clear images showing their distinguishing spots.

\section{Preliminary abundance estimate}

A summary of the model selection process is given in Table 3, where models are ranked according to AICc (Akaike information criterion is a technique that uses in-sample fit to estimate the likelihood of a model to predict/estimate future values (Akaike 1974). The top-ranked model assumes a constant capture probability, while the second-ranked model allows different capture probabilities in each year. The small difference in $-2 * \log$-likelihood suggests that the additional parameter explains little additional variation in the models. All models produced similar estimates for the leopard abundance for each year. Models that allowed for capture heterogeneity, $p$ (het),pi(.), $p$ (Year+het),pi(.), were not ranked highly by AICc which suggests some evidence of heterogeneity. The model-averaged abundance estimates for Galyat and Murree include 19, in 2017, and 9, in 2018, with 95\% confidence intervals for 16-25 (2017) and 7-13 (2018), respectively, in the effective sample area of $200 \mathrm{~km}^{2}$ derived from MMDM. 


\section{ANALYZED SPOT TO SPOT}

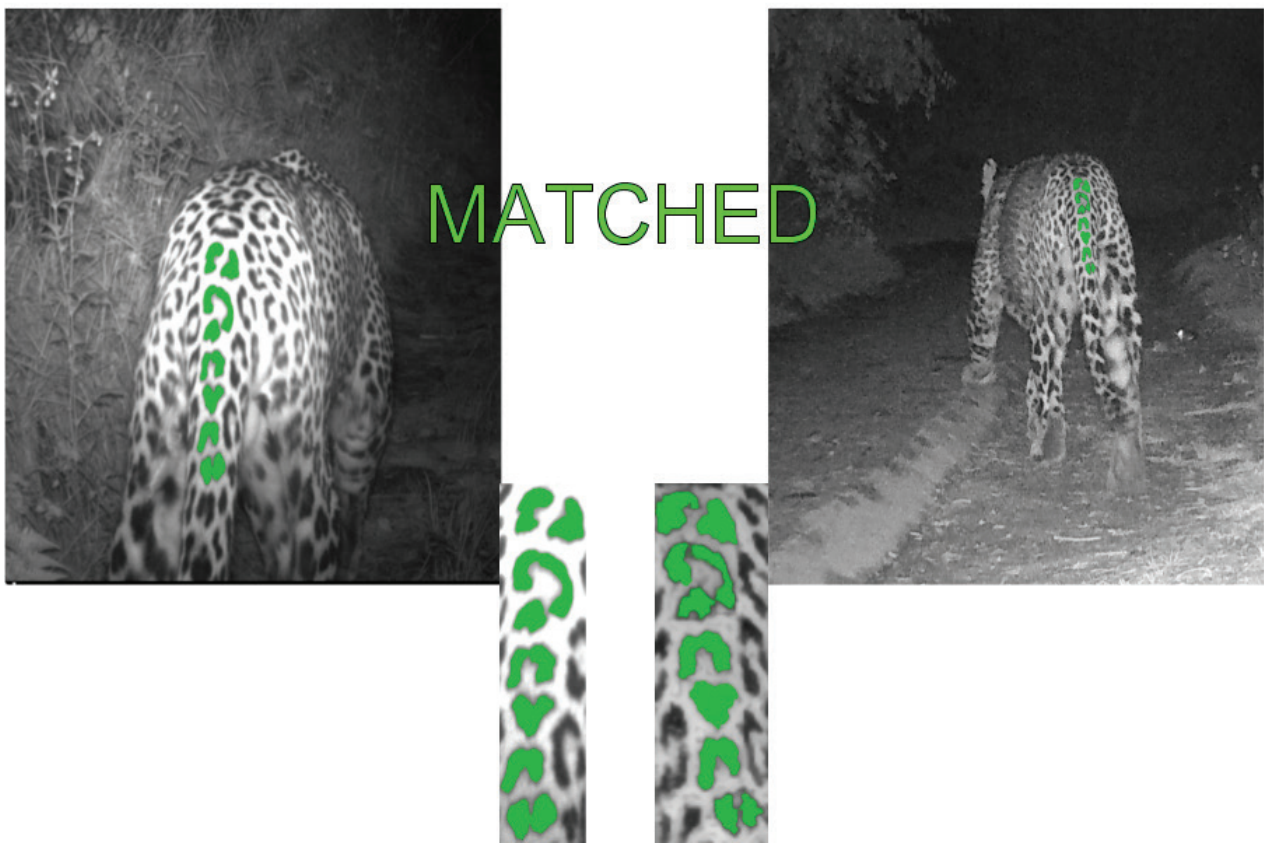

Figure 4. Example of Individual identification of the same male leopard based on its unique rosette pattern on the dorsal surface of the tail captured in two different locations at Gallies Forest Division Khyber Pakhtunkhwa Pakistan (Muhammad Asad-Lincoln University).

Table 3. Model selection results from MARK analysis for common leopard population in Gallies Forest Division and Murree Forest Division Pakistan 2017-2018.

\begin{tabular}{|c|c|c|c|c|c|c|c|c|}
\hline \multicolumn{2}{|c|}{ Without behaviour models } & \multirow{2}{*}{$\begin{array}{c}\text { AICc } \\
\text { Weights }\end{array}$} & \multirow{2}{*}{$\begin{array}{c}\text { Num. } \\
\text { Par }\end{array}$} & \multirow{2}{*}{$\begin{array}{c}-2^{*} \log - \\
\text { likelihood }\end{array}$} & \multicolumn{2}{|c|}{2017} & \multicolumn{2}{|c|}{2018} \\
\hline Model & Delta AICc & & & & Estimate & SE & Estimate & SE \\
\hline $\mathrm{p}()$. & 0.00 & 0.62 & 1 & 139.19 & 18.97 & 2.82 & 8.86 & 1.73 \\
\hline $\mathrm{p}($ Year $)$ & 1.96 & 0.23 & 2 & 139.09 & 19.36 & 3.30 & 8.53 & 1.80 \\
\hline $\mathrm{p}($ het $), \mathrm{pi}()$. & 4.13 & 0.08 & 3 & 139.19 & 18.97 & 2.82 & 8.85 & 1.73 \\
\hline p(het),pi(Year) & 5.70 & 0.04 & 4 & 138.65 & 19.91 & 3.59 & 8.88 & 1.82 \\
\hline $\mathrm{p}($ Year+het $), \mathrm{pi}()$. & 6.15 & 0.03 & 4 & 139.09 & 19.36 & 3.30 & 8.53 & 1.80 \\
\hline \multirow[t]{4}{*}{$\mathrm{p}\left(\right.$ Year $\left.^{*} \mathrm{t}\right)$} & 20.35 & 0.00 & 14 & 130.54 & 19.08 & 3.15 & 8.35 & 1.67 \\
\hline & & & & & 19.10 & 2.99 & 8.77 & 1.76 \\
\hline & & & & lower & 16.77 & & 7.61 & \\
\hline & & & & upper & 24.54 & & 12.16 & \\
\hline
\end{tabular}

The mean distances travelled by four adult male and three adult female leopards were $7 \mathrm{~km}$ and $4.6 \mathrm{~km}$, respectively. We used a $6 \mathrm{~km}$ buffer (Fig. 2), for each camera trap, derived from the mean maximum distance moved by four adult males and three 


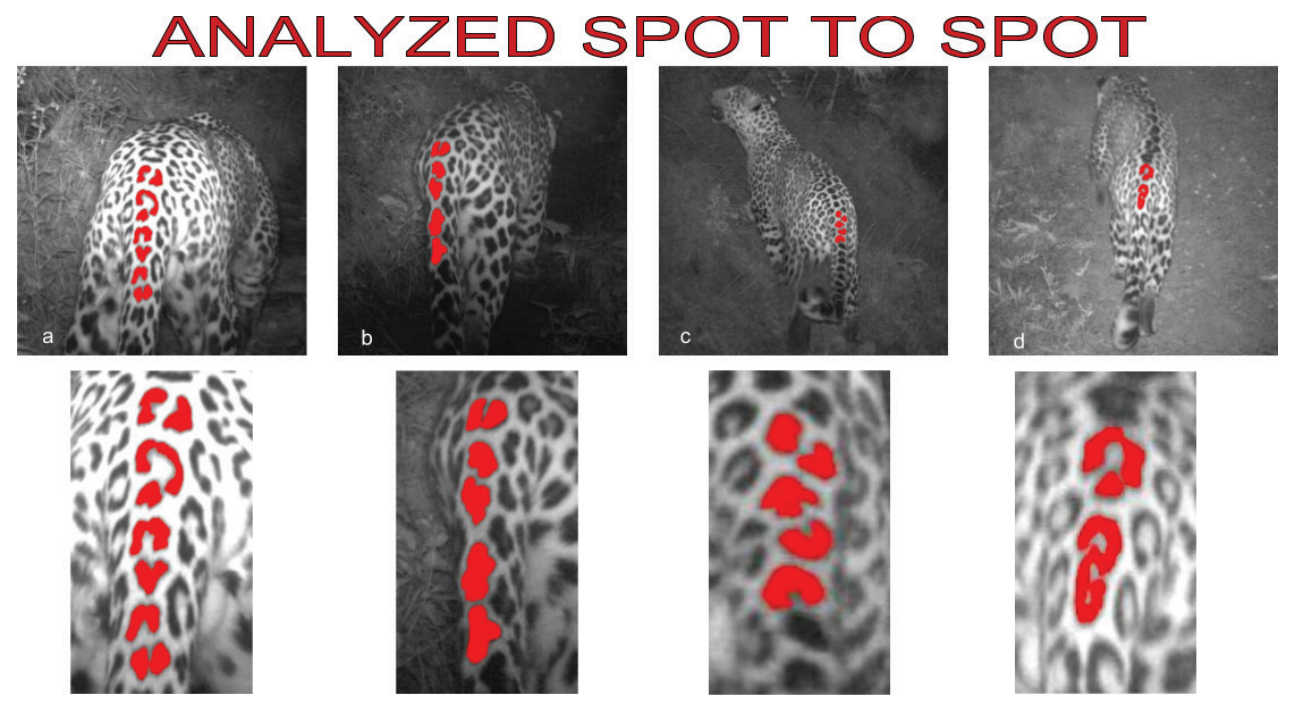

Figure 5. Example of individual differences of the leopards based on the prominent dorsal surface of a tail captured in different trails at Gallies and Murree Forest Division (Muhammad Asad-Lincoln University).

\section{ANALYZED SPOT TO SPOT NO MATCH}

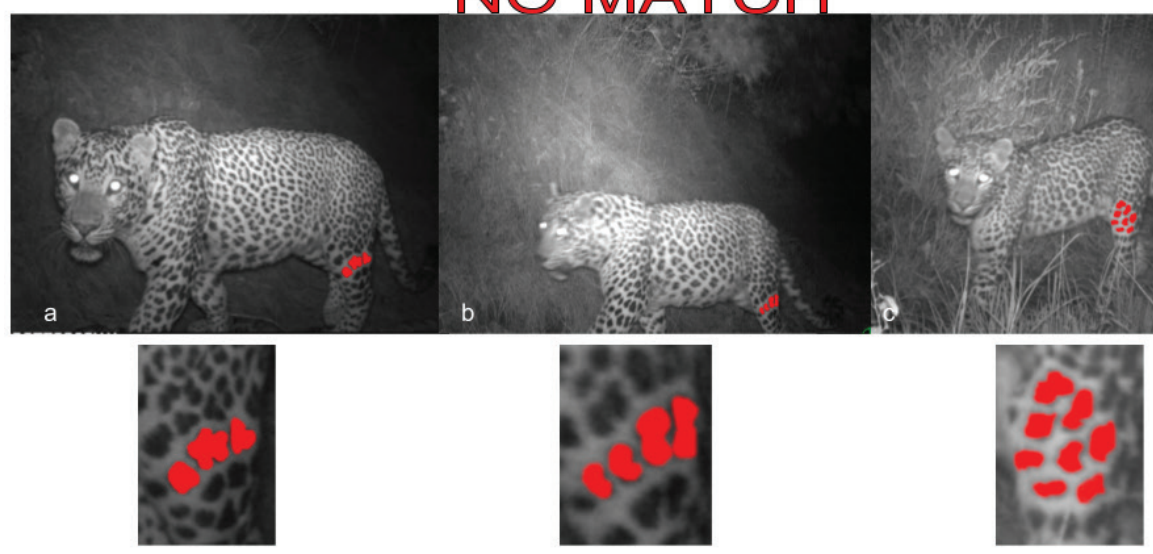

Figure 6. Example of individual differences based on the prominent left flanks of three different individuals $(\mathbf{a}, \mathbf{b}, \mathbf{c})$ captured on different trails in Gallies and Murree Forest Division.

adult females with more than one capture event on more than one camera trap (Fig. 3). Accordingly, the estimated leopard density at $200 \mathrm{~km}^{2}$ was concluded as 9.5 individuals $/ 100 \mathrm{~km}^{2}$ in 2017 and 4.5 individuals $/ 100 \mathrm{~km}^{2}$ in 2018 . The total estimated area of the Gallies and Murree forest Division is approximately $430 \mathrm{~km}^{2}$, giving a total 
population estimate, if leopards are potentially found in all habitats in this region, of 40 leopards in 2017 and 19 in 2018.

Individual sexes were identified from their external morphological characters. Eleven males and seven female leopards were identified. The sex ratio of male to female leopards in the study area, according to the camera-trapping, was 1.5:1.0. The mean encounter rate of females was higher than males on individual trails. The number of identified hotspots and leopard encounters was highest in Guzara Forest. The lowest numbers of hotspots and encounters were identified in the Cantonment and Municipal Forest (see Fig. 7).

Based on records obtained from the Wildlife Department Khyber Pakhtunkhwa and WWF-Pakistan in Abbottabad District, the mean number of leopards killed per year was $2.8 \pm 0.50$. Eight leopards also died in captivity, including two cubs. Two leopard bodies were found during our camera-trap survey, in 2018, that were not reported but that showed signs of illegal hunting (their skins were removed). The overall number of leopards that died in the winter was the same as that in the summer although more males were killed in the summer than the winter, whereas more females were killed in the winter than the summer (Fig. 9). 21 attacks on humans were registered between 2005 and 2018 and, in response, 40 leopards were killed in retaliation (Fig. 8). The mean number of leopard attacks per year was $1.5 \pm 0.60$. Ten of the attacks were lethal and the other 11 caused severe injuries.

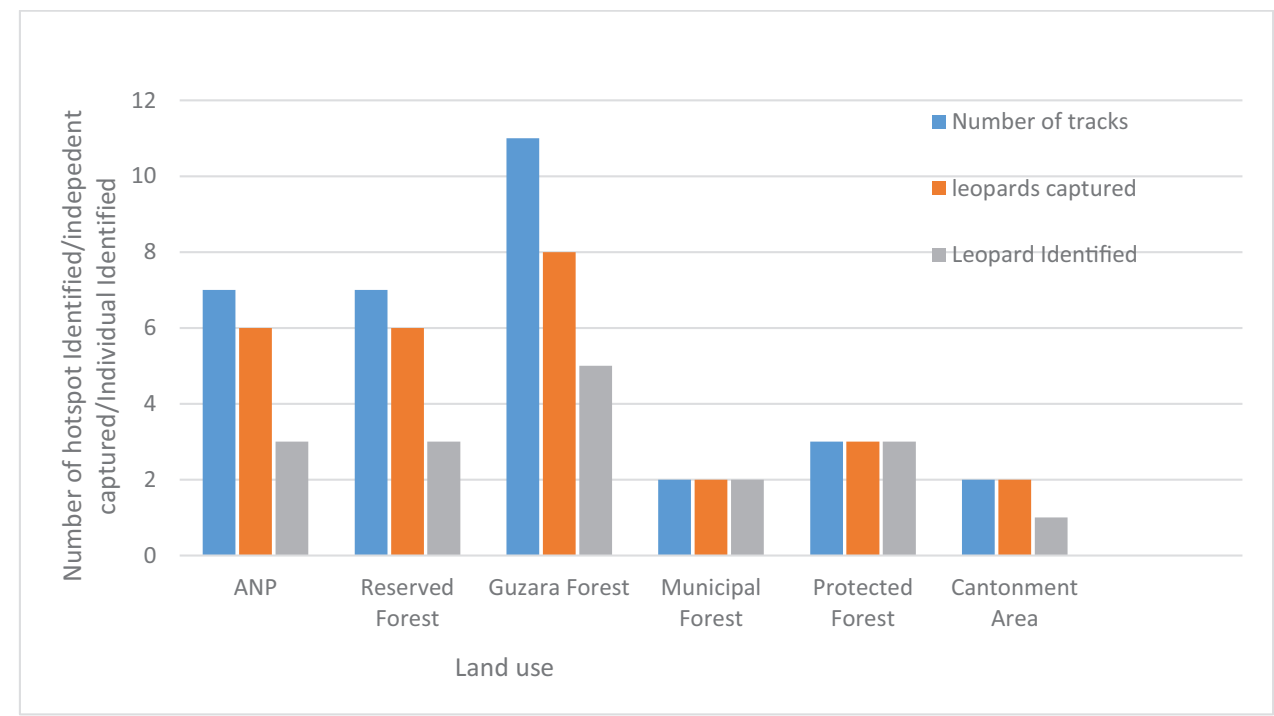

Figure 7. Number of hotspots identified in different land uses in the Galyat and Murree Forest, independently captured through camera-traps and individuals identified on each trail; Protected Forest, Reserved Forest, Municipal Forest, Ayubia National Park, Guzara Forest, and Cantonment area. 


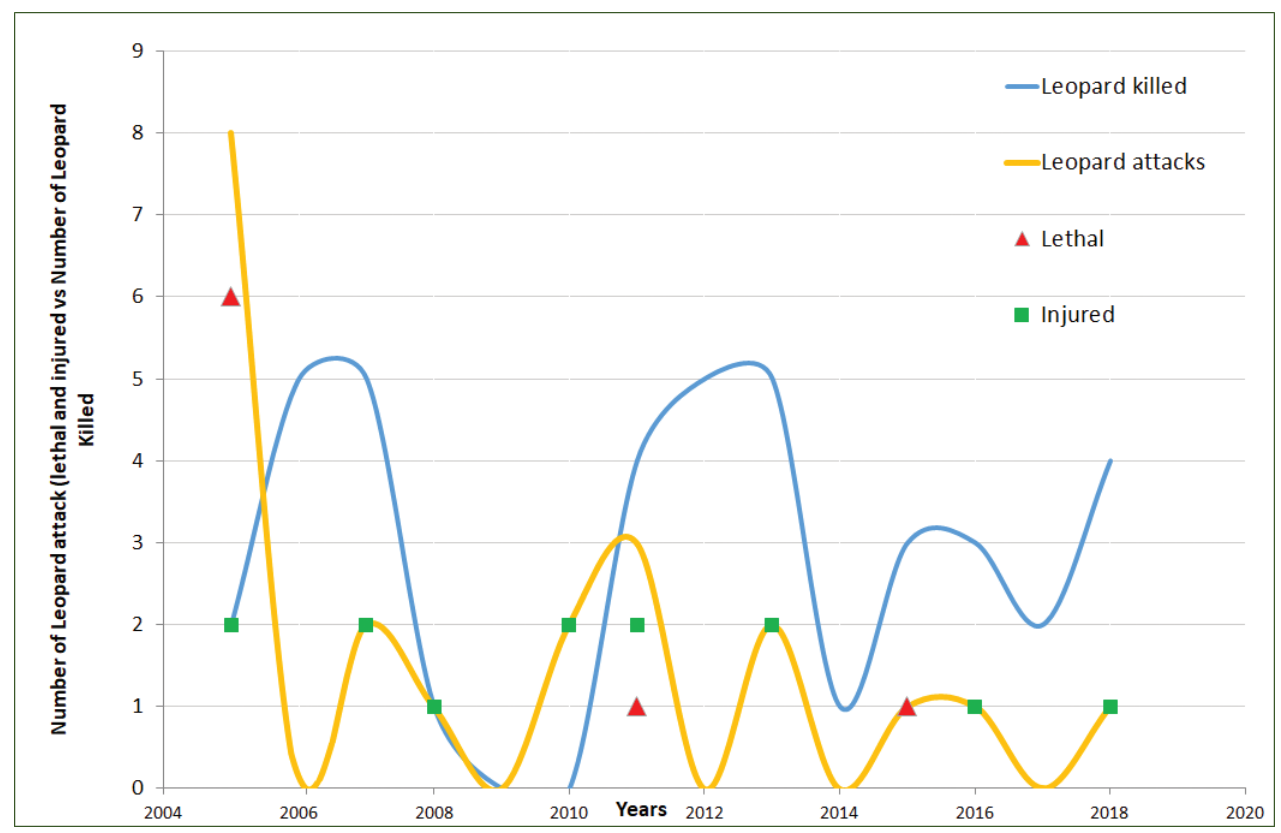

Figure 8. Number of leopard attacks on humans (red triangles lethal, green squares injuries) vs. number of leopards killed in the district of Abbottabad from 2005-2018.

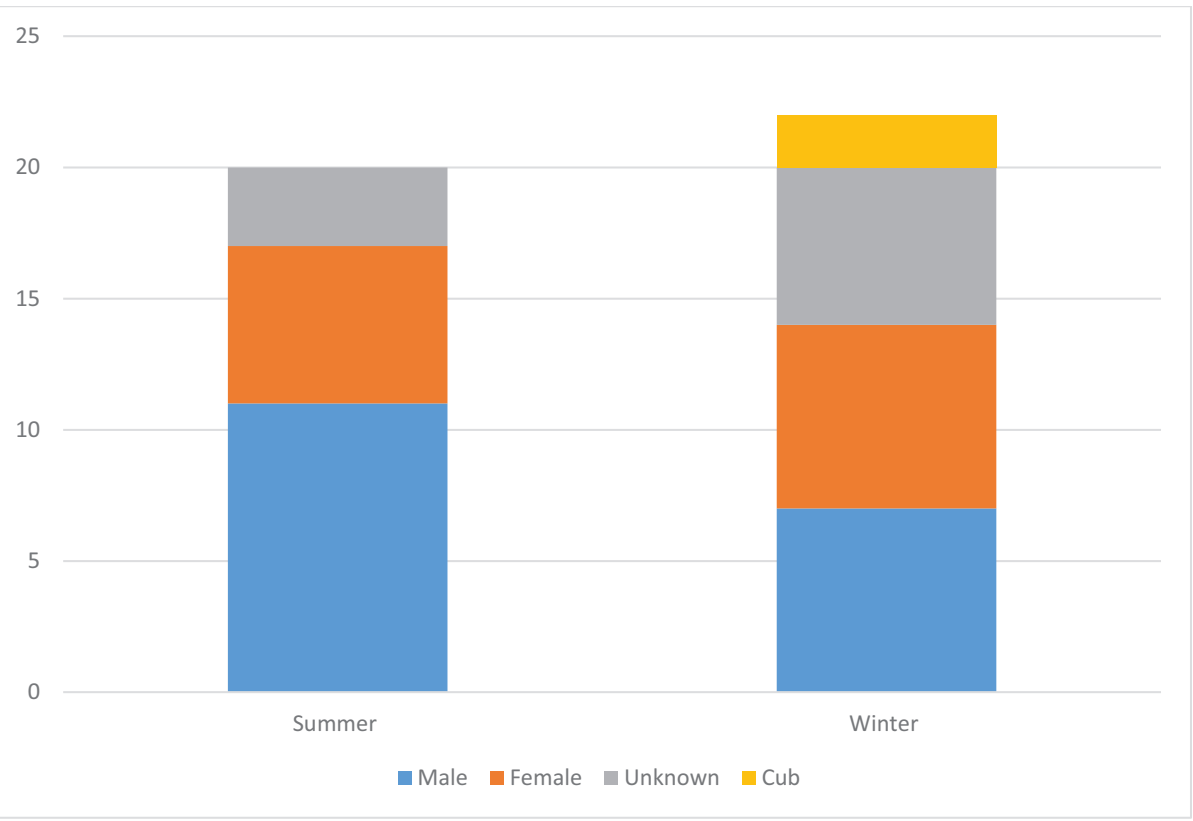

Figure 9. Number of male and female leopards that died in two seasons in the district of Abbottabad. 


\section{Discussion}

Our study confirmed the existence of leopards in the Swat, Dir and Margalla Hills regions of Pakistan. Combined with a MARK-recapture model, our camera data provided a first estimate for the leopard population in the Gallies and Murree Forest Division. The preliminary questionnaire survey was useful in identifying the information related to hotspot/trail and allowed us to cover a large area of rugged terrain, with limited accessibility, to maximise the detection probability and monitor population abundance.

The data for abundance was collected over two sampling periods, April - July 2017 and March - June 2018. Some biologists recommended a shorter duration of 2-3 months to minimise the gain/loss that occurs due to natural mortality and permanent movements into or out of the survey area during a study (Karanth 1995; Jackson et al. 2006) however, others have pressed for an extended survey in order to capture more data, maximise the accuracy and improve the confidence for a closed population (Simcharoen et al. 2007; Wang and Macdonald 2009). Our camera-traps were not distributed in a grid pattern, which is also recommended to maximise accuracy (Tobler et al. 2008). This was difficult to achieve in our study areas because of accessibility and logistics. Local knowledge and expert opinions maximised the number of captures and increased the chances of individual identification. It is crucial to identify trails that leopards may use before placing the camera-traps, as this will maximise capture probability (Balme et al. 2009; Karanth and Nichols 1998).

It was difficult to obtain quality images of both sides of a leopard's flanks on paths narrower than $2 \mathrm{~m}$ in width. We were able to match sharply defined pelages on the hind limbs and dorsal tail surface of each individual, which increased our precision when using CMR analysis in a single estimate for a given population (Alonso et al. 2015). The common leopard also changes the shape of its rosettes with the movement of its body and its orientation to the camera-trap. We found that setting the camera at an angle of $45^{\circ}$ to the track obtains clear spots and rosettes from the hind limbs or dorsal surface of tail, for individual identification. We identified individuals by comparing photos of each individual to other leopards and photos with clearer patterns were considered for comparison for individual recognition.

We are confident of our ability to identify individual leopards from photograph images and to capture histories obtained from camera-traps. We believe that cameratrapping is a viable tool for estimating the common leopard population size by maximising capture probability by placing camera traps at the priori identified hotspots located prior to the placement of camera-traps. Mixing probability estimates (Averaging effect from combining different models) suggested little evidence of heterogeneity as the estimate for pi is essentially 1 , which we suggest was due to the small sample size.

The abundance estimates obtained from the data collected during the two years of camera-trapping, are 16-24 leopards in 2017, and 7-12 in 2018. Rather than a large decline in population between the years, we think it is likely that the population has remained the same. While there were fewer captures in 2018 (71 vs 121) there were also far fewer clear images that allowed individual patterns to be identified ( $46 \%$ vs $71 \%$ ). 
If, for example, the identification rate in 2018 had also been $71 \%$ then this would have estimated a population of 12-18, which falls within the range of 2017.

We are not sure why there was an absolute change in leopard images captured between the years. The difference may have been a result of a change in individual movements around their territory or possibly due to weather. There were drought conditions in 2018 compared to 2017 (Pakistan Metrological Department). Drought conditions may have affected the prey density in the study areas, forcing leopards to extend their home range in search of prey and hence lowering the detection probability for the camera traps. Typically, studies have found little difference in the overall travelling of leopards in different seasons (Mizutani and Jewell 1998; Dickman and Marker 2005), but there has been no research on the effects of an atypical season.

The frequency of capturing a leopard on the same track may be different depending on the size of the home range (Smith 1978; Silver et al. 2004; Rozhnov et al. 2015). For example, a leopard that is captured twice a week on a track may have a smaller territory than a leopard captured once a fortnight (Personal communication). However, most studies show that home range size varies in leopard among sexes. For example, females around birthing time (Rozhnov et al. 2015) and the location of female for male home range size (Bailey 1993; Odden and Wegge 2005). There is a possibility that the decline in population was real and may be due to the killing of leopards by poachers or unreported retaliatory killings. The total number of unreported killings may skew the number from 2.8 per year to a much higher number, as we did find signs of hunting from our field surveys and camera-trap data. Another possibility could be the sampling technique, such as moving a camera trap to an adjacent location over a short time frame, which means we could have missed out leopards in that area in the second survey.

The density of leopards in our study area, at 8-12 and 3.5-6.5 leopards $/ 100 \mathrm{~km}^{2}$, is more or less similar to other CMR such as $13-14 / 100 \mathrm{~km}^{2}$ in India (Harihar et al. 2009). 3-9 leopard / $100 \mathrm{~km}^{2}$ in India (Athreya et al. 2013), Nepal (Carter et al. 2015), Cambodia (Gray and Prum 2012) Other studies have yielded relatively fewer leopards, such as 5/100 $\mathrm{km}^{2}$ in Bardia National Park, Nepal (Wegge et al. 2009) and 3-4 leopards $/ 100 \mathrm{~km}^{2}$ in Mondulkiri Protected Forest Cambodia, and Manas National Park Assam, India (Balme et al. 2009; Borah et al. 2013). The mean encounter rate of females was higher than males on individual trails, perhaps indicating that males have larger home ranges than females (Morten and Per 2005).

This study confirmed the presence of leopards in the Swat and Dir and Margalla Hills despite the fact that the local people and the local wildlife department believe that the species had disappeared from the area. There is no record of livestock depredation and retaliation by villagers in close vicinity to the forest area. Interviews with nomads did confirm the depredation in the summer seasons. However they were unsure about the actual cause of those depredations, yet the details described were similar to that of the leopard predation (e.g. bite marks, dogs missing, etc.). The nomads travel from the plains to the hills during the summer in order to find fresh pasture on which to graze their herds. They keep the livestock in the open area overnight and are more vulnerable to leopard predation. 
We recorded higher capture probabilities, 0.10 to 0.20 , according to the model selected based on AICc weight $\mathrm{p}($.$) , than reported for leopards in other studies, e.g.$ 0.04 (Wang and Macdonald 2009) and 0.02-0.10 (Borah et al. 2013) for similar habitats and this might be due to the identification of areas of high leopard use with the questionnaire survey.

Another approach used for estimating leopard density by Balme et al. (2009) was to try to fit trail count data ( $n=39$ sites) to single-season models where each pair of rows represented a unique trail where the camera-trap was later installed. Unfortunately, we did not have enough replicates for each trail, and we often observed the same leopard on several trails (using their unique rosette patterns), which would overestimate the density of leopards in the study area. Therefore, we did not rely on the trail count data in our capture analysis. Camera-trapping is more effective if the cameras are equally distributed, and cover a large area and identify each individual captured, but this is hard to achieve in rugged terrain and with animals from large home ranges (Tobler et al. 2008).

Leopards in Pakistan are sparsely distributed throughout the country (Sheikh and Molur 2004; Henschel et al. 2008; WWF-Pakistan 2014) and, hence, extensive sampling efforts and financial resources are required to cover the entire area to obtain sufficient information about their populations. One of the important outcomes of this research is to prioritise focusing on leopard hotspots from camera trap surveys, as they are a cost effective method for MARK-recapture analyses. To date, the abundance of leopards in Pakistan (Gallies, Swat, Dir, and Murree) has been anecdotal. The information about movement patterns and their dispersal behaviour is a conservation concern for many carnivores (Kanagaraj et al. 2013).

We observed that leopards use the Guzara Forest around the reserve areas extensively as a part of their home range. Based on information obtained from the Wildlife Department Khyber Pakhtunkhwa and WWF-Pakistan, 70\% of the leopards that were killed by humans for revenge were outside the reserve area (Guzara Forest) and near the villages, and mostly during the winter season (Personal communication). The Guzara Forest received comparatively less snow in the protected areas, which may explain why leopards were more likely to be found there in winter and close to human settlements (Personal communication.).

Conservation efforts should focus more on hotspots identified in the Guzara Forest surrounding the Reserved Forest as this may reduce human-leopard conflicts. These forests allow leopards to extend their movements while searching for food. This extension also occasionally led to livestock depredation by leopards and resulted in the revenge killing of the leopards. Immediate compensation for losses of the livestock owners and a comprehensive awareness raising programme for schoolchildren together with the other members of the local community may significantly reduce the conflict between humans and leopards.

Some schools are located near those observational area and children travel through these routes to reach schools. Random attacks by leopards on children sometime create a stressful situation for children. Avoiding leopard trails during dawn and dusk can minimise the chances of such attacks. 
We strongly recommend using a modified version of our protocol, in regions and areas where the presence of leopard populations is ambiguous. Our study suggests that camera-trapping, combined with a MARK-recapture method, can be useful for estimating the abundance in leopard habitat over time given the maximum number of individuals identified. Locating the remaining leopard population needs to be a high priority as this will, then, allow a focus on other conservation issues for this species.

The ultimate threat to the leopards and their occurrence in this habitat is extensive legal and illegal hunting activities. The Wildlife Department has issued numerous licences to locals for hunting the birds as part of the revenue generation programme. If a person is reported for illegal hunting, they are subjected to a low-value penalty and then re-issued with a licence. Then a person can effectively hunt anything since there are no checks and balances. Illegal hunting has created a disturbing condition for leopards that push them away from relative habitats. The other threats to leopards in this area are habitat degradation, unplanned infrastructure development, encroachment by humans, and an alarming use of the natural prey base.

Despite the limitation of camera placement in a grid, this camera-trap study provides the first evidence of the species presence in this area. The design method provided a reasonable way of estimating $\mathrm{p}$ (capture probability in this case) and we maximised the likelihood of capture by identifying hotspots. The mark recapture framework presents an advantage, as the individuals are identifiable from their unique pelage pattern. Although our method cannot provide absolute certainty with regard to abundance, we believe that the estimate we obtained from Mark provides a high degree of confidence when compared with actual field data of (identified individuals). However, to develop a sound conservation plan additional camera-traps studies on natural densities, habitat and the associated threats are needed in this region.

In conclusion, this research provides baseline information for leopard conservation and the mitigation of human and leopard conflicts for the Gallies and Murree Forest Division. The hotspots can be used to monitor population trends and any demographic changes through time. We also recommend future studies in different seasons and for longer periods. Our study suggests that the most productive conservation efforts may be beyond the protected area with special consideration given to those corridors (Guzara Forest) to ensure the long-term viability of leopard populations.

\section{Acknowledgement}

We are grateful to the Wildlife Department Khyber Pakhtunkhwa Pakistan, Punjab Wildlife Department for granting permission to conduct this camera trapping study in northern Pakistan. This study was funded by research grants from Lincoln University New Zealand and Rufford Small Grant UK. We thank all the staff Wildlife Department Khyber Pakhtunkhwa, WWF-Pakistan for facilitating the study. We are thankful to the anonymous reviewer who provided useful comments and suggestion on the draft manuscript. We also greatly appreciate the assistance provided by Darryl Mackenzie during data analysis. 


\section{References}

Abbas S, Qamer FM, Rana AD, Hussain N, Saleem R (2010) Application of object based image analysis for forest cover assessment of moist temperate Himalayan forest in Pakistan. The International Archives of the Photogrammetry. Remote Sensing and Spatial Information Sciences 39: 4-46.

Abdollahi S (2015) Modeling habitat requirements of leopard (Panthera pardus) using genetic Algorithm in Golestan National Park. Environmental Resource Research 3(2): 151-162.

Ahmad M, Sultana S, Fazl-i-Hadi S, Hadda TB, Rashid S, Zafar M, Khan Muhammad PZ (2014) An Ethnobotanical study of medicinal plants in high mountainous region of Chail valley (District Swat- Pakistan). Journal of Ethnobiology and Ethnomedicine 10(1): 36. https://doi.org/10.1186/1746-4269-10-36

Ahmed J, Mahmood F (1998) Changing perspectives on forest policy. London International Institute for Environment and Development IIED, 140.

Akaike H (1974) A new look at the statistical model identification. In: Parzen E, Tanabe K, Kitagawa G (Eds) Selected papers of Hirotuge Akaike. Springer series in statistics). Springer, New York. https://doi.org/10.1007/978-1-4612-1694-0_16

Alexander JS, Zhang C, Shi K, Riordan P (2016) A granular view of a snow leopard population using camera traps in Central China. Biological Conservation 197: 27-31. https://doi. org/10.1016/j.biocon.2016.02.023

Alonso RS, McClintock BT, Lyren LM, Boydston EE, Crooks KR (2015) Mark-Recapture and Mark-Resight Methods for Estimating Abundance with Remote Cameras: A Carnivore Case Study. Plose one10(3): e0123032. https://doi.org/10.1371/journal.pone.0123032

Asad M, Martoni F, Ross JG, Waseem M, Abbas F, Paterson AM (2019) Assessing subspecies status of leopards (Panthera pardus) of northern Pakistan using mitochondrial DNA. PeerJ 7: e7243. https://doi.org/10.7717/peerj.7243

Ashraf I, Saeed U, Shahzad N, Gill J, Parvez S, Raja A (2014) Delineating legal forest boundaries to combat illegal forest encroachments: A case study in Murree Forest Division, Pakistan 11: 263-286. https://doi.org/10.1007/978-94-017-8757-4_13

Athreya V, Belsare A (2007) Human - leopard conflict management guidelines. http://environmentportal.in/files/Conflict\%20management\%20manual.pdf

Athreya V, Odden M, Linnell JD, Krishnaswamy J, Karanth KU (2013) Big cats in our backyards: Persistence of large carnivores in a human dominated landscape in India. PLoS One 8(3): e57872. https://doi.org/10.1371/journal.pone.0057872

Athreya V, Odden M, Linnell JD, Krishnaswamy J, Karanth KU (2016) A cat among the dogs: Leopard Panthera pardus diet in a human-dominated landscape in western Maharashtra, India. Oryx 50(01): 156-162. https://doi.org/10.1017/S0030605314000106

Bailey TN (1993) The African leopard: ecology and behavior of a solitary felid. Columbia University Press 75(4):1093-1094. https://doi.org/10.7312/bail90198

Balme GA, Hunter LTB, Slotow R (2009) Evaluating methods for counting cryptic carnivores. The Journal of Wildlife Management 73(3): 433-441. https://doi. org/10.2193/2007-368 
Balme GA, Hunter L, Braczkowski AR (2012) Applicability of age-based hunting regulations for African leopards. PLoS One 7(4): e35209. https://doi.org/10.1371/journal. pone.0035209

Bashir T, Bhattacharya T, Poudyal K, Sathyakumar S, Qureshi Q (2014) Integrating aspects of ecology and predictive modelling: Implications for the conservation of the leopard cat (Prionailurus bengalensis) in the eastern Himalaya. Acta Theriologica 59(1): 35-47. https:// doi.org/10.1007/s13364-013-0145-x

Bino G, Ramp D, Kingsford RT (2014) Identifying minimal sets of survey techniques for multi-species monitoring across landscapes: An approach utilising species distribution models. International Journal of Geographical Information Science 28(8): 1674-1708. https://doi. org/10.1080/13658816.2013.871016

Borah J, Sharma T, Das D, Rabha N, Kakati N, Basumatary A, Vattakaven J (2013) Abundance and density estimates for common leopard Panthera pardus and clouded leopard Neofelis nebulosa in Manas National Park, Assam. Oryx 48(1): 149-155. https://doi.org/10.1017/ S0030605312000373

Brodie JF (2009) Is research effort allocated efficiently for conservation? Felidae as a global case study. Biodiversity and Conservation 18(11): 2927-2939. https://doi.org/10.1007/ s10531-009-9617-3

Brown JL, Orians GH (1970) Spacing patterns in mobile animals. Annual Review of Ecology Evolution and Systematics 1(1): 239-262. https://doi.org/10.1146/annurev. es.01.110170.001323

Burt WH (1943) Territoriality and home range concepts as applied to mammals. Journal of Mammalogy 24(3): 346-352. https://doi.org/10.2307/1374834

Cardillo M, Purvis A, Sechrest W, Gittleman JL, Bielby J, Mace GM (2004) Human population density and extinction risk in the world's carnivores. PLoS Biology 2(7): e197. https:// doi.org/10.1371/journal.pbio.0020197

Carter N, Jasny M, Gurung B, Liu J (2015) Impacts of people and tigers on leopard spatiotemporal activity patterns in a global biodiversity hotspot. Global Ecology and Conservation 3(3): 149-162. https://doi.org/10.1016/j.gecco.2014.11.013

Dickman AJ, Marker LL (2005) Factors affecting leopard (Panthera pardus) spatial ecology, with particular reference to Namibian farmlands: research article. South African Journal of Wildlife Research 35(2): 105-115.

Fahrig L (2003) Effects of habitat fragmentation on biodiversity. annual review of Ecology, Evolution, and systematics 34(1): 487-515. https://doi.org/10.1146/annurev.ecolsys.34.011802.132419

FAO (2007) State of The World's Forests. http://www.fao.org/3/a-a0773e.pdf [Retrieved September 20, 2018]

Fusaro JL, Conner MM, Conover MR, Taylor TJ, Kenyon Jr MW, Sherman JR, Ernest HB (2017) Comparing urban and wildland bear densities with a DNA-based capture-markrecapture approach. Human-Wildlife Interactions 11(1): 50-63.

Ghalib SA, Jabbar A, Khan AR, Zehra A (2007) Current status of mammals of Balochistan. Pakistan Journal of Zoology 39(2): 117-122. 
Gray TNE, Prum SSA (2012) leopard density in post-conflict landscape, Cambodia: Evidence from spatially explicit capture-recapture. The Journal of Wildlife Management 76(1): 163169. https://doi.org/10.1002/jwmg.230

Harihar A, Pandav B, Goyal S (2009) Density of leopards (Panthera pardus) in the Chilla range of Rajaji National Park, Uttarakhand (73). https://doi.org/10.1515/MAMM.2009.007

Harmsen BJ, Foster RJ, Doncaster CP (2011) Heterogeneous capture rates in low density populations and consequences for capture-recapture analysis of camera-trap data. Population Ecology 53(1): 253-259. https://doi.org/10.1007/s10144-010-0211-z

Heilbrun RD, Silvy NJ, Tewes ME, Peterson MJ (2003) Using automatically triggered cameras to individually identify bobcats. Wildlife Society Bulletin (1973-2006) 31(3): 748-755.

Henschel P, Ray J (2003) Leopard in African Rainforest: Survey and monitoring techniques. Wildlfie Conservation Society. https://www.panthera.org/cms/sites/default/files/documents/LeopardManual_English_lowres.pdf

Henschel P, Hunter L, Breitenmoser U, Purchase N, Packer C, Khorozyan IG, BreitenmoserWursten C (2008) Panthera pardus. The IUCN Red List of Threatened Species. https://doi. org/10.2305/IUCN.UK.2008.RLTS.T15954A5329380.en

Hunter L, Henschel P, Ray J (2013) Panthera pardus. Kingdon JS, Hoffmann M (Eds) Mammals of africa volume V: Carnivores, pangolins, equids and rhinocerose. Bloomsbury, London, 544.

Jackson RM, Roe JD, Wangchuk R, Hunter DO (2006) Estimating snow leopard population abundance using photography and capture-recapture techniques. Wildlife Society Bulletin 34(3): 772-781. https://doi.org/10.2193/0091-7648(2006)34[772:ESLPAU]2.0.CO;2

Jacobson AP, Gerngross P, Lemeris JRJ, Schoonover RF, Anco C, Breitenmoser-Wursten C, Dollar L (2016) Leopard (Panthera pardus) status, distribution, and the research efforts across its range. PeerJ 4: e1974. https://doi.org/10.7717/peerj.1974

Jewell PA (1966) The concept of home range in mammals. Symposia of the Zoological Society of London 18: 85-109.

Kabir M, Ghoddousi A, Awan MS, Awan MN (2013) Assessment of human-leopard conflict in Machiara National Park, Azad Jammu and Kashmir, Pakistan. European Journal of Wildlife Research 60(2): 291-296. https://doi.org/10.1007/s10344-013-0782-z

Kanagaraj R, Wiegand T, Kramer-Schadt S, Goyal SP (2013) Using individual-based movement models to assess inter-patch connectivity for large carnivores in fragmented landscapes. Biological Conservation 167: 298-309. https://doi.org/10.1016/j.biocon.2013.08.030

Karanth KU (1995) Estimating tiger Panthera tigris populations from camera-trap data using capture-recapture models. Biological Conservation 71(3): 333-338. https://doi. org/10.1016/0006-3207(94)00057-W

Karanth KU, Nichols JD (1998) Estimation of tigers densities in India using photographic capture and recaptures. Ecology 79(8): 2852-2862. https://doi.org/10.1890/00129658(1998)079[2852:EOTDII]2.0.CO;2

Karki JB, Pandav B, Jnawali SR, Shrestha R, Pradhan NMB, Lamichane BR, Khanal P, Subedi N, Jhala YV (2013) Estimating the abundance of Nepal's largest population of tigers Panthera tigris. Oryx 49(1): 150-156. https://doi.org/10.1017/S0030605313000471

Kery M, Gardner B, Monnerat C (2010) Predicting species distributions from checklist data using site-occupancy models. Journal of Biogeography 37(10): 1851-1862. https://doi. org/10.1111/j.1365-2699.2010.02345.x 
Khan MZ, Ghalib SA, Khan AR, Zehra A, Yasmeen R, Hussain B, Begum A (2013) Current habitat, distribution and status of the mammals of Khirthar protected area complex, Sindh. Canadian Journal of Pure and Applied Science 7(2): 2347-2356.

Khorozyan I, Malkhasyan AG, Abramov AV (2008) Presence-absence surveys of prey and their use in predicting leopard (Panthera pardus) densities: A case study from Armenia. Integrative Zoology 3(4): 322-332. https://doi.org/10.1111/j.1749-4877.2008.00111.x

Kshettry A, Vaidyanathan S, Athreya V (2017) Leopard in a tea-cup: A study of leopard habitatuse and human-leopard interactions in north-eastern India. PLoS One 12(5): e0177013. https://doi.org/10.1371/journal.pone.0177013

Kshettry A, Vaidyanathan S, Athreya V (2018) Diet Selection of Leopards (Panthera pardus) in a Human-Use Landscape in North-Eastern India. Tropical Conservation Science 11. https://doi.org/10.1177/1940082918764635

Laguardia A, Kamler JF, Li S, Zhang C, Zhou Z, Shi K (2015) The current distribution and status of leopards Panthera pardus in China. Oryx 1-7. https://doi.org/10.1017/ s0030605315000988

Lodhi A (2007) Conservation of leopards in Ayubia National Park Pakistan. (Master), University of Montana. https://scholarworks.umt.edu/cgi/viewcontent.cgi?article=1257\&context=etd

MacKenzie DI (2005) What Are the issues with presence-absence data for wildlife Managers? The Journal of Wildlife Management 69(3): 849-860. https://doi.org/10.2193/0022541X(2005)069[0849:WATIWP]2.0.CO;2

Maffei L, Noss AJ (2008) How Small is too Small? Camera trap survey areas and density estimates for ocelots in the Bolivian Chaco. Biotropica 40(1): 71-75. https://doi.org/10.1111/ j.1744-7429.2007.00341.x

Manly B, McDonald L, Thomas DL, McDonald TL, Erickson WP (2002) Resource selection by animals: statistical design and analysis for field studies ( $2^{\text {nd }}$ edn). Kluwer, Dordrecht, Netherlands and Springer Science \& Business Media.

Mizutani F, Jewell PA (1998) Home-range and movements of leopards (Panthera pardus) on a livestock ranch in Kenya. Journal of Zoology 244(2): 269-286. https://doi. org/10.1111/j.1469-7998.1998.tb00031.x

Mondal K, Gupta S, Bhattacharjee S, Qureshi Q, Sankar K (2012a) Prey selection, food habits and dietary overlap between leopard Panthera pardus (Mammalia: Carnivora) and re-introduced tiger Panthera tigris (Mammalia: Carnivora) in a semi-arid forest of Sariska Tiger Reserve, Western India. The Italian Journal of Zoology 79(4): 607-616. https://doi.org/1 $0.1080 / 11250003.2012 .687402$

Mondal K, Sankar K, Qureshi Q (2012b) Factors influencing the distribution of leopard in a semiarid landscape of Western India. Acta Theriologica 58(2): 179-187. https://doi. org/10.1007/s13364-012-0109-6

Mondol S, Navya R, Athreya V, Sunagar K, Selvaraj VM, Ramakrishnan U (2009) A panel of microsatellites to individually identify leopards and its application to leopard monitoring in human dominated landscapes. BMC Genetics 10(1): 79. https://doi.org/10.1186/14712156-10-79

Morten O, Per W (2005) Spacing and activity patterns of leopards Panthera pardus in the Royal Bardia National Park, Nepal. Wildlife Biology 11(2): 145-152. https://doi. org/10.2981/0909-6396(2005)11[145:SAAPOL]2.0.CO;2 
Nowell K, Jackson P (1996) Wild cats: status survey and conservation action plan. IUCN Gland. O'Brien SJ, Johnson WE (2005) Big cat genomics. Annual Review of Genomics and Human Genetics 6(1): 407-429. https://doi.org/10.1146/annurev.genom.6.080604.162151

Odden M, Wegge P (2005) Spacing and activity patterns of leopards Panthera pardus in the Royal Bardia National Park, Nepal. Wildlife Biology 11(2): 145-152. https://doi. org/10.2981/0909-6396(2005)11[145:SAAPOL]2.0.CO;2

Otis DL, Burnham KP, White GC, Anderson DR (1978) Statistical inference from capture data on closed animal populations. Wildlife Monographs (62): 3-135.

Qi J, Shi Q, Wang G, Li Z, Sun Q, Hua Y, Jiang G (2015) Spatial distribution drivers of Amur leopard density in northeast China. Biological Conservation 191: 258-265. https://doi. org/10.1016/j.biocon.2015.06.034

Quaglietta L, Fonseca VC, Hájková P, Mira A, Boitani L (2013) Fine-scale population genetic structure and short-range sex-biased dispersal in a solitary carnivore,Lutra lutra. Journal of Mammalogy 94(3): 561-571. https://doi.org/10.1644/12-MAMM-A-171.1

Ray-Brambach RR, Stommel C, Rödder D (2018) Home ranges, activity patterns and habitat preferences of leopards in Luambe National Park and adjacent Game Management Area in the Luangwa Valley, Zambia. Mammalian Biology 92: 102-110. https://doi.org/10.1016/j. mambio.2017.11.002

Ripple WJ, Estes JA, Beschta RL, Wilmers CC, Ritchie EG, Hebblewhite M, Berger J, Elmhagen B, Letnic M, Nelson MP, Shmitz OJ, Smith DW, Wallach AD, Wirsing AJ (2014) Status and ecological effects of the world's largest carnivores. Science 343(6167): 1241484. https://doi.org/10.1126/science.1241484

Roberts TJ (1977) The mammals of Pakistan. Ernest Benn Limited, London, 26: 361 pp.

Rovero F, Zimmermann F, Berzi D, Meek P (2013) which camera trap type and how many do I need?" A review of camera features and study designs for a range of wildlife research applications. Hystrix, the Italian Journal of Mammalogy 24(2): 148-156.

Rowcliffe JM, Field J, Turvey ST, Carbone C (2008) Estimating animal density using camera traps without the need for individual recognition. Journal of Applied Ecology 45(4): 1228-1236. https://doi.org/10.1111/j.1365-2664.2008.01473.x

Royle JA, Dorazio RM (2008) Hierarchical modeling and inference in ecology. Academic Press, London, $444 \mathrm{pp}$.

Rozhnov VV, Chistopolova MD, Lukarevskii VS, Hernandez-Blanco JA, Naidenko SV, Sorokin PA (2015) Home range structure and space use of a female Amur leopard, Panthera pardus orientalis (Carnivora, Felidae). The Biological Bulletin 42(9): 821-830. https://doi. org/10.1134/S1062359015090095

Sanei A, Zakaria M (2011c) Survival of the Persian leopard (Panthera pardus saxicolor) in Iran: Primary threats and human-leopard conflicts. Asia Life Sciences (Supplement 7): 31-39.

Sanei A, Zakaria M, Yusof E, Roslan M (2011a) Estimation of leopard population size in a secondary forest within Malaysia's capital agglomeration using unsupervised classification of pugmarks. Tropical Ecology 52(2): 209-217.

Sanei A, Zakaria M, Hermidas Sh (2011b) Prey composition in the Persian leopard distribution range in Iran. Asia Life Sciences (Supplement 7): 19-30.

Sanei A, Mousavi M, Mousivand M, Zakaria M (2012) Assessment of the Persian leopard mortality rate in Iran. In: Arifin B, et al. (Eds) Proceedings of UMT $11^{\text {th }}$ International 
Annual Symposium on Sustainability Science and Management. Universiti Malaysia Terengganu.

Sanei A, Mousavi M, Kiabi BH, Masoud MR, Gord Mardi E, Mohamadi H, Shakiba M, Baran Zehi A, Teimouri M, Raeesi T (2016) Status assessment of the Persian leopard in Iran. Cat News 10(Special Issue): 43-50.

Scheibe KM, Eichhorn K, Wiesmayr M, Schonert B, Krone O (2008) Long-term automatic video recording as a tool for analysing the time patterns of utilisation of predefined locations by wild animals. European Journal of Wildlife Research 54(1): 53-59. https://doi. org/10.1007/s10344-007-0108-0

Sharma RK, Jhala Y, Qureshi Q, Vattakaven J, Gopal R, Nayak K (2010) Evaluating capture-recapture population and density estimation of tigers in a population with known parameters. Animal Conservation 13(1): 94-103. https://doi.org/10.1111/j.1469-1795.2009.00305.x

Shehzad W, Nawaz MA, Pompanon F, Coissac E, Riaz T, Shah SA, Taberlet P (2014) Forest without prey: Livestock sustain a leopard Panthera pardus population in Pakistan. Oryx 49(02): 248-253. https://doi.org/10.1017/S0030605313001026

Sheikh KM, Molur S (2004) Status and Red List of Pakistan's Mammals based on the Pakistan Mammal Conservation Assessment \& Management Plan. 312 pp.

Silver SC, Ostro LET, Marsh LK, Maffei L, Noss AJ, Kelly MJ, Wallace RB, Gomez H, Ayala G (2004) The use of camera traps for estimating jaguar Panthera onca abundance and density using capture/recapture analysis. Oryx 38(2): 148-154. https://doi.org/10.1017/ S0030605304000286

Simcharoen S, Pattanavibool A, Karanth KU, Nichols JD, Kumar NS (2007) How many tigers Panthera tigris are there in Huai Kha Khaeng wildlife sanctuary, Thailand? An estimate using photographic capture-recapture sampling. Oryx 41(4): 447-453. https://doi. org/10.1017/S0030605307414107

Smith RM (1978) Movement patterns and feeding- behaviour of the leopard in the Rhodes Matopos National Park, Rhodesia. Carnivore 1: 58-69.

Soisalo MK, Cavalcanti SMC (2006) estimating the density of a jaguar population in the Brazilian Pantanal using camera-traps and capture-recapture sampling in combination with GPS radio-telemetry. Biological Conservation 129(4): 487-496. https://doi.org/10.1016/j.biocon.2005.11.023

Sollmann R, Tôrres NM, Furtado MM, de Almeida Jácomo AT, Palomares F, Roques S, Silveira L (2013) Combining camera-trapping and noninvasive genetic data in a spatial capturerecapture framework improves density estimates for the jaguar. Biological Conservation 167: 242-247. https://doi.org/10.1016/j.biocon.2013.08.003

Spong G, Johansson M, Bjorklund M (2000) High genetic variation in leopards indicates large and long-term stable effective population size. Molecular Ecology 9(11): 1773-1782. https://doi.org/10.1046/j.1365-294x.2000.01067.x

Stein AB, Hayssen V (2013) Panthera pardus (Carnivora: Felidae). Mammalian Species 45(900): 30-48. https://doi.org/10.1644/900.1

Stein AB, Athreya V, Gerngross P, Balme G, Henschel P, Karanth U, Miquelle D, RostroGracia S,Kamler JF, Laguardia A, Khorozyan I, Ghoddousi A (2016) Panthera pardus. The IUCN red list of threatened species. https://doi.org/10.2305/IUCN.UK.2016-1.RLTS. T15954A50659089.en 
Sundaresan SR, Riginos C, Abelson ES (2011) Management and analysis of camera trap data: Alternative approaches (Response to Harris et al. 2010). Bulletin of the Ecological Society of America 92(2): 188-195. https://doi.org/10.1890/0012-9623-92.2.188

Theile S (2003) Fading Footsteps: The Killing and Trade of Snow Leopards Density. http:// www.trafficj.org/publication/03_Fading_Footprint.pdf [Retrieved October 2, 2018]

Thornton DH, Pekins CE (2015) Spatially explicit capture-recapture analysis of bobcat (Lynx rufus) density: Implications for mesocarnivore monitoring. Wildlife Research 42(5): $394-$ 404. https://doi.org/10.1071/WR15092

Tobler MW, Powell GVN (2013) Estimating jaguar densities with camera traps: Problems with current designs and recommendations for future studies. Biological Conservation 159: 109-118. https://doi.org/10.1016/j.biocon.2012.12.009

Tobler MW, Carrillo-Percastegui SE, Leite Pitman R, Mares R, Powell G (2008) An evaluation of camera traps for inventorying large- and medium-sized terrestrial rainforest mammals. Animal Conservation 11(3): 169-178. https://doi.org/10.1111/j.1469-1795.2008.00169.x

Trolle M, Kery M (2003) Estimation of ocelot density in the Pantanal using capture-recapture analysis of camera-trapping data. Journal of Mammalogy 84(2): 607-614. https://doi. org/10.1644/1545-1542(2003)084<0607:EOODIT>2.0.CO;2

Trolliet F, Huynen MC, Vermeulen C, Hambuckers A (2014) Use of camera traps for wildlife studies. A review. Biotechnologie, Agronomie, Société et Environnement 18(3): 446-454.

Uphyrkina O, O’Brien SJ (2003) Applying molecular genetic tools to the conservation and action plan for the critically endangered far eastern leopard (Panthera pardus orientalis). Comptes Rendus Biologies 326: 93-97. https://doi.org/10.1016/S1631-0691(03)00044-1

Wang SW, Macdonald DW (2009) The use of camera traps for estimating tiger and leopard populations in the high altitude mountains of Bhutan. Biological Conservation 142(3): 606-613. https://doi.org/10.1016/j.biocon.2008.11.023

Wegge P, Odden M, Pokharel CP, Storaas T (2009) Predator-prey relationships and responses of ungulates and their predators to the establishment of protected areas: A case study of tigers, leopards and their prey in Bardia National Park, Nepal. Biological Conservation 142(1): 189-202. https://doi.org/10.1016/j.biocon.2008.10.020

WhiteGC, Burnham KP (1999) Program MARK: survival estimation from populations of marked animals. Bird Study 46(sup1): 120-139. https://doi.org/10.1080/00063659909477239

Williams BK, Nichols JD, Conroy MJ (2002) Analysis and Management of Animal Populations: Modeling Estimation and Decision Making. UK Academic Press, San Diego and London, 817 pp.

WWF-Pakistan (2014) Common leopard conservation project https://www.wwfpak.org/ factsheets/pdf/Common\%20leopard.pdf [Retrieved October 5, 2018] 